\title{
AVALIAÇÃO POR FOTOINTERPRETAÇÃO DAS ÁREAS DE ABRANGÊNCIA DOS DIFERENTES ESTADOS DA EROSÃO ẢCELERADA DO SOLO EM CANAVIAIS E POMARES DE CITROS
}

\author{
WALTER POLITANO ${ }^{1}$, TERESA C. T. PISSARRA ${ }^{2}$
}

\begin{abstract}
RESUMO: Este estudo foi realizado com o objetivo de avaliar os estados de erosão acelerada do solo presente em áreas com canaviais e pomares de citros localizados na região administrativa de Ribeirão Preto - SP. Foram empregadas fotografias aéreas verticais, na escala aproximada de 1:40.000, do vôo da cobertura aerofotográfica da região citrícola do Estado de 1988. O estudo foi realizado identificando-se e delimitando-se todas as áreas de abrangência de cinco estados da erosão acelerada do solo presentes nos canaviais e pomares de citros. A presença da erosão acelerada severa a extremamente severa foi constatada tanto nos canaviais como nos pomares de citros, nas quatro unidades de solos de ocorrências principais na área de estudo. Os valores da extensão total das áreas de abrangência dos estados da erosão 2 a 5 (processos erosivos intensos a extremamente intensos) revelaram forte impacto sobre o desenvolvimento das culturas, degradando o solo agrícola e afetando a qualidade da água. As principais diferenças, quanto à extensão total das áreas de abrangência dos diferentes estados da erosão presente, foram identificadas principalmente entre os Argissolos e os Latossolos, e entre os dois estágios de desenvolvimento das culturas. As condições de solo exposto foram verificadas nas áreas recentemente plantadas com cana-de-açúcar ou citros, explicitando-se a grande necessidade de empregar, nessas condições, práticas conservacionistas.
\end{abstract}

PALAVRAS-CHAVE: erosão acelerada, cana-de-açúcar, cultura de citros.

\section{EVALUATION OF AREAS OF DIFFERENT STATES OF ACCELERATED EROSION OF SOIL IN SUGAR CANE PLANTATIONS AND CITRUS ORCHARDS UTILIZING PHOTOINTERPRETATION TECHNIQUES}

\begin{abstract}
This study was conducted with the objective of evaluating the states of accelerated erosion of soil in areas with sugar cane and citrus orchards located in Ribeirão Preto - SP, Brazil, using photointerpretation techniques. Vertical aerial photos, scale of 1:40.000 from the aerophotographic covering of the citric area of the State in 1988 have been used. The map of the land used and accelerated erosion was made in all the areas with five states of the soil accelerated erosion present in the sugar cane plantations and citrus orchards. The study showed the presence of a serious problem caused by the accelerated erosion in the sugar cane plantations and citrus orchards. The presence of areas of severe to extremely severe erosion was verified in the sugar cane plantations and in the citrus orchards, in four soil units, in the study area. The values of the total extension of the areas of the states of erosion 2 to 5 (intense to extremely intense erosive processes) revealed a strong impact of the accelerated erosion on the development of the cultures. This can cause a degradation of the agricultural land and can affect the distribution and quality of the water. The conditions of exposed soil were verified in the areas recently planted with sugar cane or citrus, and those conditions need better agricultural management.
\end{abstract}

KEYWORDS: accelerated erosion, sugar cane, citrus.

\footnotetext{
${ }^{1}$ Prof. Titular, Depto. de Engenharia Rural, UNESP, Jaboticabal - SP, Fone: (0XX16) 3209.2637, walter.politano@itelefonica.com.br

${ }^{2}$ Prof. Dr., Depto. de Engenharia Rural, UNESP, Jaboticabal - SP, pissarra@ fcav.unesp.br.

Recebido pelo Conselho Editorial em: 30-10-2002

Aprovado pelo Conselho Editorial em: 2-2-2005
}

Eng. Agríc., Jaboticabal, v.25, n.1, p.242-252, jan./abr. 2005 


\section{INTRODUÇÃO}

As culturas de cana-de-açúcar e de citros são, na atualidade, as principais formas de uso agrícola do solo na região administrativa de Ribeirão Preto - SP. A lavoura canavieira iniciou-se nessa região logo após o declínio da cafeicultura, ocorrendo de imediato grande expansão. No início da década de 1940, Ribeirão Preto e Piracicaba já eram identificadas como as regiões canavieiras do Estado (AUDI, 1965).

A citricultura também se expandiu no interior paulista nas primeiras décadas do século XX, concentrando-se inicialmente na região de Limeira. Após o declínio da cafeicultura, avançou para o planalto ocidental paulista, mas concentrou-se principalmente no eixo Araraquara - Bebedouro.

As duas culturas expandiram-se muito rapidamente nessa região a partir da década de 1970 , causando grande transformação econômica e social provocada, principalmente, pelo desenvolvimento de um complexo agroindustrial sucroalcooleiro (BELO, 1991).

$\mathrm{Na}$ lavoura canavieira, por expandir-se inicialmente em áreas de topografia suave e com solos muito produtivos, principalmente pelo Latossolos Roxos e Latossolos Vermelho-Escuros-orto, segundo RANZANI (1976), não foram identificados inicialmente problemas graves de erosão acelerada. A própria cultura, por suas características fisionômicas e sistemas de plantio, também contribui para a conservação do solo, dificultando a ação erosiva da água das chuvas, conforme salientaram BARROS (1961) e FORBES (1961). Mas, na fase inicial de desenvolvimento da cultura, o solo permanece exposto por um período prolongado, facilitando a incidência de processos erosivos intensos e/ou muito intensos, na forma de ravinas ou sulcos (KOFFLER, 1980).

Entretanto, a expansão da cultura para áreas novas com solos arenosos pobres e/ou com topografias mais íngremes tem aumentado significativamente os riscos de erosão intensa e muito intensa. Nas partes baixas das encostas ou vertentes, a erosão é geralmente mais intensa, pois o escoamento superficial da água desenvolve-se com maior volume e velocidade, aumentando a sua ação erosiva. Nessas posições, também ocorrem maiores riscos de enxurradas, as quais invadem os canaviais localizados à jusante (POLITANO et al., 1980). O uso contínuo de grade pesada, a circulação de máquinas e veículos no interior canaviais e o preparo do solo sob condições inadequadas de umidade também contribuem para o aumento da intensidade e abrangência dos processos erosivos, porque são formadas camadas de subsuperfície muito compactadas que restringem fortemente a infiltração da água no solo (CASAGRANDE, 1981; FULLEN \& REED, 1986; SILVA \& RIBEIRO, 1992).

Como é grande a extensão de solo exposto entre plantas, o problema da erosão acelerada pode ser mais grave nos pomares de citros que nos canaviais, apesar de a disposição das árvores (pomares formados) em alinhamentos em nível proteger bastante o solo (POLITANO et al., 1993). Alguns fatores, como o clima, tipo de solo, topografia, estágio de desenvolvimento do pomar e a densidade do revestimento do solo com vegetação herbácea entre plantas, também influenciam positiva ou negativamente na manifestação de processos erosivos intensos e/ou muito intensos, podendo até causar ravinamento muito forte em pomares de citros localizados em áreas acidentadas, conforme MODENEZI \& JORDÃO (1992) e TRICART (1961).

Pelas possibilidades de fortes impactos negativos sobre o ambiente e de prejuízos socioeconômicos para a região, os quais podem ser provocadas pela manifestação de processos erosivos intensos e muito intensos nas áreas cultivadas dessas duas culturas, destaca-se a alta importância da realização de estudos técnicos e científicos tendo como propósitos melhor avaliar o problema da erosão acelerada em canaviais e pomares de citros. Nesse enfoque, em face das possibilidades de relacionar as características da imagem fotográfica com a existência de diferentes riscos de manifestação da erosão acelerada e, de acordo com as naturezas das duas culturas e dos tipos 
de solos presentes na área de estudo, este trabalho foi desenvolvido com o objetivo de avaliar as presenças, juntamente com as respectivas áreas de abrangência, dos diversos estados de erosão acelerada do solo presentes em canaviais e pomares de citros cultivados em Argissolos VermelhoAmarelo e Latossolos Vermelhos e Latossolos Vermelho-Amarelos, textura média, situados na parte oeste da região de governo de Ribeirão Preto - SP.

\section{MATERIAL E MÉTODOS}

A área de estudo consiste numa extensão aproximada de $4.400 \mathrm{~km}^{2}$ com predomínio das culturas da cana-de-açúcar e citros localizadas na parte oeste da região de governo de Ribeirão Preto - SP. A posição geográfica é definida pelas coordenadas latitudes $20^{\circ} 30^{\prime} \mathrm{S}$ a $21^{\circ} 45^{\prime} \mathrm{S}$ e longitudes $49^{\circ} 25^{\prime} \mathrm{W}$ a $48^{\circ}$ 20’W (BRASIL, 1971). Essa área engloba os municípios de Itápolis, Matão, Taquaritinga, Dobrada, Santa Ernestina, Guariba, Jaboticabal, Monte Alto, Cândido Rodrigues, Fernando Prestes, Vista Alegre do Alto, Taiaçu, Taiúva e parte do Município de Pitangueiras. Com relação ao uso do solo, a cana-de-açúcar predomina nos municípios de Santa Ernestina, Guariba e Jaboticabal, e os pomares de citros, conforme observações em campo, se apresentam com expressão muito alta nos demais municípios.

O clima, segundo o Sistema de Koëppen, é o mesotérmico de inverno seco (Cwa), com temperaturas médias dos meses mais quentes e mais frios, respectivamente, maior que $22{ }^{\circ} \mathrm{C}$ e menor que $18{ }^{\circ} \mathrm{C}$. A precipitação anual varia entre 1.300 e $1.500 \mathrm{~mm}$ de chuvas (AYOADE, 1991).

A geologia é composta pelos arenitos Bauru - fácies conglomerática $(\mathrm{Kb})$ e rochas efusivas básicas da Formação Serra Geral (SÃO PAULO, 1974).

As unidades de solos relacionadas com esses materiais são, respectivamente, os Solos Podzólicos Vermelho-Amarelos e Latossolos Roxos (SÃO PAULO, 1981), além das unidades Latossolos Vermelho-Amarelos e Latossolos Vermelho-Escuros, textura média, que são formadas a partir de areias não consolidadas, provavelmente do cenozóico, que se apresentam, em parte da área, sobrepostas aos materiais geológicos acima citados (PENTEADO \& RANZANI, 1971).

A classificação dessas unidades, pelo Sistema Brasileiro de Classificação de Solos, segundo CAMARGO et al. (1987), é, respectivamente, Solos Podzólicos Vermelho-Amarelos, abrupto, eutróficos, A moderado, textura média (Pml); Solos Podzólicos Vermelho-Amarelos, distrófico, A moderado, textura média (Pln); Latossolos Roxos, eutrófico, A moderado, textura argilosa/muito argilosa (LR); Latossolos Vermelho-Escuros, álico, A moderado, textura média (LEa) e Latossolos Vermelho-Amarelos, álico, A moderado e textura média (LVa). De acordo com OLIVEIRA et al. (1999), as unidades de solos presentes na área de estudo são identificadas como Argissolos VermelhoAmarelos (PVA); Argissolos Vermelho-Amarelos (PVA4) - Eutróficos, abrúpticos, textura arenosa/média, relevo suave ondulado e ondulado + Argissolos Vermelho-Amarelos, Eutróficos, textura arenosa/média e média, relevo suave ondulado, ambos A moderado e PVA3 - Eutróficos, textura arenosa/média e média, relevo suave ondulado + Argissolos Vermelho-Amarelos, Eutróficos, abrúpticos, textura arenosa/média, relevo suave ondulado e ondulado, ambos A moderado; Latossolos Vermelhos (LV) - Latossolos Vermelhos (LV15) - Distroférricos, A moderado e proeminente, textura Argilosa, relevo suave ondulado e plano e LV45 - Distróficos, A moderado, textura média, relevo plano e suave ondulado; não sendo, portanto, identificada por esses autores, a unidade Latossolos Vermelho-Amarelos.

O relevo é subtabular de planalto, com altitudes variando entre 400 e $750 \mathrm{~m}$. Apresenta-se com colinas amplas na classe suave ondulado nos Latossolos; colinas amplas a médias, numa transição entre as classes suave ondulado e ondulado, nos Argissolos (PVA) provenientes de materiais retrabalhados dos arenitos Bauru-fácies conglomerática, e com colinas médias e classe de relevo 
ondulado nos Podzólicos Vermelho-Amarelos (Pml) formados diretamente a partir dos arenitos Bauru - fácies conglomerática. A rede hidrográfica apresenta-se com os modelos ou padrões de drenagem dendríticos, subdendríticos nos arenitos Bauru e subparalelos nas rochas efusivas básicas (POLITANO, 1992).

A vegetação originária é a floresta latifoliada tropical (AZEVEDO, 1968), também identificada como floresta estacional (JOLY, 1970). Atualmente, de acordo com observações de campo, essa cobertura florestal apresenta-se praticamente extinta, ocorrendo somente algumas áreas de remanescentes muito pequenas. $\mathrm{O}$ uso do solo é realizado principalmente com as culturas de cana-deaçúcar e citros, sendo também identificados, além das culturas de ciclo curto, campos de pastoreio e culturas de manga e goiaba.

Um conjunto de fotografias aéreas verticais, o qual faz parte do levantamento da região citrícola do Estado realizado em 1988, foi empregado como material básico na elaboração do mapa de base e na fotointerpretação das duas comunidades de plantas e da erosão acelerada do solo presente nas áreas de cultivo dessas duas comunidades. As fotografias empregadas apresentam-se com as seguintes características: pancromáticas e interferentes, com escala aproximada de 1:40.000. Os templetes e a folha de base foram feitos com o filme poliester Rhodia 50 micra de espessura. As cartas topográficas da Coleção Carta do Brasil, na escala 1:50.000 (BRASIL, 1971), foram empregadas na determinação dos limites dos municípios e como apoio na montagem das fotografias aéreas, que foi realizada por triangulação radial gráfica, segundo descrição de LOPES VERGARA (1971), com modificações de acordo com POLITANO (1994).

A atividade de fotointerpretação, que foi acompanhada por diversas visitas de campo no decorrer do estudo, foi efetuada por meio da análise estereoscópica de fotografias aéreas interferentes que recobrem a área de estudo, utilizando-se de um estereoscópio de espelho marca Zeiss. Nessa atividade, as áreas identificadas na imagem fotográfica foram delimitadas sobre os templetes que cobrem as fotografias aéreas, sendo, em seguida, transferidas com a mesma escala das fotografias para uma folha de base. As medidas de tamanho das áreas mapeadas foram obtidas empregando-se o planímetro polar A. OTT.

Os padrões fotográficos dos canaviais novos e formados foram identificados nas fotografias aéreas em função da análise dos aspectos fisionômicos dessa comunidade de plantas que são registrados pela imagem fotográfica, a saber: plantas herbáceas em touceiras, com colmos cilíndricos e maciços e folhas paralelinérvias, lanceoladas, largas, rígidas, muito compridas com cores verde-claras e/ou médias; talhões formando maciços com porte arbustivo e telhados contínuos e uniformes que acompanham a conformação do terreno (canavial adulto); e talhões com portes herbáceo e arbustivo, com plantas dispostas em alinhamentos geralmente em nível (canavial soca e/ou recém-plantados) e telhados descontínuos. As principais características dos talhões são: maciços, expressões de contornos predominantemente com formas geométricas e graus de destaque médios e altos; tonalidades claras e médias; telhados planos e contínuos; textura aveludada muito fina e fina; tonalidades claras (cana madura e cana recém-plantada), médias (folhagem verde) e escuras (cana queimada); e porte herbáceo médio (canavial formado); talhões com tonalidades muito claras e claras intercaladas por linhas de tonalidades mais escuras e telhado descontínuo; portes herbáceos ou arbustivos baixos (canavial soca e/ou recém-plantado) (POLITANO, 1994).

Os padrões fotográficos dos pomares de citros novos e formados foram identificados pelos seguintes aspectos fisionômicos dessa cultura: árvores de portes baixo/médio (pomares formados) e arbustos (pomares novos e/ou em formação); estrutura organizada com plantas dispostas em alinhamentos retos e/ou em nível; silhuetas esféricas, cores verde-médias e verde-escuras. Esses padrões se apresentam conforme segue: estrutura organizada em que as plantas estão dispostas em alinhamentos retos ou em nível; tonalidades da superfície do terreno geralmente mais claras que os 
círculos regularmente espaçados representativos da distribuição das plantas no pomar (identificados pela observação estereoscópica como semi-esferas geralmente escuras). Os pomares formados diferem dos pomares novos pelo tamanho desses círculos, o qual reflete o porte e o volume, dando a indicação da idade do pomar (POLITANO, 1994).

Com relação à erosão acelerada presente nas áreas de canaviais e pomares de citros, cabe inicialmente destacar que a mesma se refere à erosão hídrica causada pela água das chuvas em áreas cultivadas. É denominada como erosão acelerada porque se manifesta sob condições ambientais alteradas pela ação do homem (ação antrópica), sendo, conseqüentemente, muito mais intensa que a erosão normal ou geológica, a qual ocorre nos ambientes naturais, não alterados pelo homem.

Entende-se como estado da erosão acelerada a condição presente no solo numa determinada época ou ocasião, que se manifesta em função do estágio de desenvolvimento do processo erosivo e, portanto, do risco de erosão, que é inferido em função das condições climáticas, do tipo de solo, da topografia e da natureza da cultura. No caso da erosão presente, seria ideal escolher como unidades de estudo as classes de erosão, mas o emprego das fotografias aéreas apresenta limitações para essa finalidade por não permitir uma discriminação completa das classes de erosão laminar e em sulco. Assim sendo, neste trabalho, adotando-se o levantamento aerofotogramétrico da região citrícola do Estado de São Paulo, realizado em 1988, foram estabelecidos os seguintes estados da erosão acelerada presente no solo: 1. erosão laminar ligeira e/ou moderada - não são visíveis alterações da imagem fotográfica que podem ser relacionadas com a incidência da erosão acelerada do solo; 2. erosão intensa em sulcos superficiais e rasos - a imagem fotográfica se apresenta com filamentos sinuosos na direção da encosta ou declive, cujas tonalidades são geralmente mais claras que das áreas que os contornam (nos canaviais formados, esses sulcos não são identificados nas fotografias aéreas porque o telhado dessa comunidade de plantas, por ser muito denso, não revela os elementos da análise visual indicativos desse tipo de sulcos); 3. erosão intensa, com sulcos variando de rasos a profundos, com freqüências raras a comuns - imagem fotográfica apresenta-se com alterações dos elementos forma, textura e tonalidade, os quais são características da presença de sulcos de erosão, permitindo, desse modo, identificar pela observação estereoscópica os sulcos e, em seguida, relacioná-los com as respectivas freqüências de ocorrência; 4. erosão muito intensa, com sulcos predominantemente profundos, freqüientes e/ou muito freqüentes - idem 3 , muitos sulcos por unidade de área, e 5. erosão em voçorocas - erosão extremamente intensa, revelada por alterações muito características da imagem fotográfica que permitem ver com muito destaque, nas imagens fotográficas, as ravinas apresentando grandes dimensões, sendo, então, possível identificar os aspectos relacionados com a forma e o tamanho (POLITANO, 1994).

\section{RESULTADOS E DISCUSSÃO}

Nas fotografias aéreas, identificaram-se, tanto nos canaviais como nos pomares de citros, a predominância de áreas com terraços e o cultivo em nível destinado ao controle da erosão acelerada. Além dessas práticas de controle, foram identificados com razoável frequiência entre linhas da cultura, o revestimento do solo com vegetação herbácea nos pomares e o recobrimento da superfície do solo com a palhada da cana em canaviais recentemente cortados, constatando-se, dessa forma, adoção muito generalizada de práticas conservacionistas nas duas culturas.

As extensões totais de canaviais e pomares cítricos de cada unidade de solo são apresentadas na Tabela 1, sendo as mesmas discriminadas de acordo com o estágio de desenvolvimento da cultura.

Esse conjunto de dados mostra que, no final da década de 1980, época da realização do vôo de cobertura aerofotogramétrica da região citrícola do Estado, existia distribuição bem definida das duas culturas na região, que ocorria de acordo com a variação da topografia e a distribuição das unidades de solos. Pelos dados obtidos, confirmou-se a tradição de que a cana-de-açúcar predomina em áreas mais 
planas ligadas com as ocorrências dos Latossolos. A cultura de citros, ao contrário, apresentava-se com maior expressão em áreas mais acidentadas, associadas com a presença dos Podzólicos VermelhoAmarelos. A lavoura canavieira estava concentrada nos quadrantes nordeste e sudeste da área de estudo, enquanto a cultura dos citros se destacava mais no noroeste e sudoeste da área de estudo, em áreas pertencentes à zona citrícola do eixo Araraquara-Bebedouro. Em face dessas formas de distribuição das duas culturas, as usinas de açúcar e álcool e as indústrias de sucos cítricos também se localizavam de modo regionalizado.

TABELA 1. Extensões totais, por unidade de solos, dos canaviais e pomares de citros, referentes ao ano de 1988.

\begin{tabular}{crrrrrrrr}
\hline & \multicolumn{3}{c}{ Solos } & \multicolumn{3}{c}{ Canaviais } & \multicolumn{3}{c}{ Pomares de Citros } \\
\hline Unidades & $\begin{array}{c}\text { Área } \\
\text { (ha) }\end{array}$ & $\%$ & $\begin{array}{c}\text { Área Total } \\
\text { (ha) }\end{array}$ & $\begin{array}{c}\text { Novos } \\
\text { (ha) }\end{array}$ & $\begin{array}{c}\text { Formados } \\
\text { (ha) }\end{array}$ & $\begin{array}{c}\text { Área Total } \\
\text { (ha) }\end{array}$ & $\begin{array}{c}\text { Novos } \\
\text { (ha) })\end{array}$ & $\begin{array}{c}\text { Formados } \\
(\text { ha })\end{array}$ \\
\hline Pml & 126.709 & 28,80 & 28.932 & 7.489 & 21.443 & 45.639 & 13.862 & 31.777 \\
Pln & 185.886 & 42,25 & 38.830 & 10.261 & 28.569 & 54.223 & 15.273 & 38.950 \\
LEA/LR & 89.696 & 20,39 & 60.235 & 8.350 & 51.885 & 6.331 & 1.232 & 5.099 \\
LVA/LR & 37.659 & 8,56 & 13.047 & 2.285 & 10.762 & 4.992 & 1.044 & 3.948 \\
\hline Total & 439.950 & 100,00 & 141.044 & 28.385 & 112.659 & 111.185 & 31.411 & 79.774 \\
\hline
\end{tabular}

As duas comunidades de plantas encontravam-se, no final da década de 1980, em fase de expansão na área de estudo, conforme mostram os valores muito expressivos das áreas ocupadas pelas comunidades novas (CN e PN). Os canaviais expandiam-se em áreas novas, passando a ocupar áreas com arenitos - Bauru, cuja topografia é mais acidentada, situadas fora dos limites da região canavieira do Estado, onde predominam os solos Podzólicos Vermelho-Amarelos.

Os dados de extensões totais das duas comunidades vegetais ressaltam a pujança dos complexos agroindustriais de produção de açúcar e álcool e de sucos cítricos, que são os principais responsáveis pela economia muito destacada da região no cenário nacional. Eles também propiciavam aumento das condições favoráveis de mercado de trabalho, tanto para a mão-de-obra não especializada como para a especializada.

Quanto ao estudo da erosão acelerada do solo, na Tabela 2, são apresentados os dados quanto à extensão total da abrangência de cada estado da erosão presente em cada unidade de solo, sendo os mesmos discriminados de acordo com o estágio do desenvolvimento das duas culturas. O conjunto global dos dados mostra que, por ocasião do final da década de 1980, a erosão acelerada do solo se constituía num fator muito importante de degradação do solo agrícola, tanto nos canaviais como nos pomares de citros.

Extensões muito consideráveis com processos erosivos intensos e muito intensos causavam, além do empobrecimento do solo, alteração muito perceptível da conformação da superfície do terreno geradas pelo escavamento das posições mais altas localizadas a montante e pelo soterramento das posições mais baixas do terreno, representadas principalmente pelas planícies de inundação ou várzeas.

Esse processo de degradação diminui a capacidade de produção do solo, dificulta a mecanização da agricultura e afeta prejudicialmente o aproveitamento e a qualidade da água das chuvas que atinge o terreno.

Os depósitos coluviais formados pelo acúmulo de materiais provenientes das vertentes prejudicam os ambientes muito úmidos e encharcados das várzeas, podendo até criar ambientes totalmente inóspitos para a reprodução da fauna presente. 
TABELA 2. Áreas de abrangência de cinco estados da erosão acelerada do solo presentes em canaviais e pomares de citros localizados na região administrativa de Ribeirão Preto - SP.

\begin{tabular}{|c|c|c|c|c|c|c|}
\hline \multirow{3}{*}{$\begin{array}{c}\text { Unidades } \\
\text { de } \\
\text { Solos }\end{array}$} & \multirow{3}{*}{$\begin{array}{c}\text { Estados da Erosão } \\
\text { Acelerada do } \\
\text { Solo }\end{array}$} & \multirow{3}{*}{$\begin{array}{c}\text { Área } \\
\text { de } \\
\text { Abrangência }\end{array}$} & \multicolumn{4}{|c|}{ Comunidades de Plantas } \\
\hline & & & \multirow{2}{*}{\multicolumn{2}{|c|}{$\begin{array}{c}\text { Canaviais } \\
\text { Novos - CN Formados-PF }\end{array}$}} & \multicolumn{2}{|c|}{ Pomares de Citros } \\
\hline & & & & & Novos - PN & Formados-PF \\
\hline \multirow{2}{*}{ Pml } & & ha & 2.548 & 13.091 & 3.910 & 24.019 \\
\hline & & $\%$ & 34,07 & 61,05 & 28,21 & 76,55 \\
\hline \multirow{2}{*}{ Pln } & 1. Erosão & ha & 3.998 & 25.591 & 5.052 & 30.605 \\
\hline & laminar: & $\%$ & 38,96 & 75,59 & 33,08 & 78,58 \\
\hline \multirow{2}{*}{$\mathrm{LEa} / \mathrm{LR}$} & ligeira/moderada & ha & 5.113 & 48.316 & 976 & 4.849 \\
\hline & & $\%$ & 61,23 & 93,12 & 79,22 & 95,10 \\
\hline \multirow{2}{*}{$\mathrm{LVa} / \mathrm{LR}$} & & ha & 1.777 & 10.088 & 143 & 2.789 \\
\hline & & $\%$ & 77,77 & 93,74 & 13,70 & 70,74 \\
\hline \multirow{2}{*}{ Pml } & & ha & 1.677 & - & 6.503 & 2.446 \\
\hline & & $\%$ & 22,39 & - & 46,91 & 6,27 \\
\hline \multirow{2}{*}{ Pln } & 2. Erosão intensa: & ha & 2.808 & - & 5.464 & 3.491 \\
\hline & sulcos & $\%$ & 27,36 & - & 35,78 & 8,96 \\
\hline \multirow{2}{*}{$\mathrm{LEa} / \mathrm{LR}$} & superficiais & ha & 2.293 & - & 219 & 58 \\
\hline & e rasos & $\%$ & 27,46 & - & 17,78 & 1,14 \\
\hline \multirow{2}{*}{$\mathrm{LVa} / \mathrm{LR}$} & & ha & 113 & - & 643 & 416 \\
\hline & & $\%$ & 4,95 & - & 5,97 & 10,54 \\
\hline \multirow{2}{*}{ Pml } & & ha & 1.760 & 7.714 & 1.699 & 3.769 \\
\hline & & $\%$ & 23,50 & 36,11 & 12,26 & 12,01 \\
\hline \multirow{2}{*}{ Pln } & & ha & 1.726 & 4.015 & 2.878 & 3.902 \\
\hline & 3. Erosão intensa: & $\%$ & 16,82 & 14,05 & 18,84 & 10,01 \\
\hline \multirow{2}{*}{ LEa/LR } & sulcos ocasionais & ha & 642 & 2.987 & 37 & 128 \\
\hline & a comuns & $\%$ & 7,69 & 5,76 & 3,00 & 2,51 \\
\hline \multirow{2}{*}{$\mathrm{LVa} / \mathrm{LR}$} & & ha & 195 & 573 & 154 & 118 \\
\hline & & $\%$ & 8,53 & 5,32 & 14,75 & 2,99 \\
\hline \multirow{2}{*}{ Pml } & & ha & 1.384 & 608 & 1.428 & 962 \\
\hline & & $\%$ & 18,48 & 2,84 & 10,30 & 3,07 \\
\hline \multirow{2}{*}{ Pln } & 4. Erosão muito & ha & 1.275 & 1.730 & 1.857 & 952 \\
\hline & intensa: sulcos & $\%$ & 12,43 & 6,06 & 12,16 & 2,44 \\
\hline \multirow{2}{*}{$\mathrm{LEa} / \mathrm{LR}$} & freqüentes/muito & ha & 302 & 582 & 0 & 64 \\
\hline & freqüentes & $\%$ & 3,62 & 1,12 & 0,0 & 1,26 \\
\hline \multirow{2}{*}{$\mathrm{LVa} / \mathrm{LR}$} & & ha & 200 & 101 & 104 & 363 \\
\hline & & $\%$ & 8,75 & 0,94 & 9,96 & 9,19 \\
\hline \multirow{2}{*}{ Pml } & & ha & 120 & 0 & 322 & 181 \\
\hline & & $\%$ & 1,60 & 0,00 & 2,32 & 0,58 \\
\hline \multirow{2}{*}{ Pln } & 5. Erosão & ha & 454 & 1.230 & 22 & 0 \\
\hline & extremamente & $\%$ & 4,42 & 4,31 & 0,14 & 0,00 \\
\hline I Eo/I D & intensa: & ha & 0 & 0 & 0 & 0 \\
\hline $\mathrm{LEa} / \mathrm{LR}$ & voçorocas & $\%$ & 0,00 & 0,00 & 0,00 & 0,00 \\
\hline$I_{\mathrm{I}} \mathrm{V} / \mathrm{I} \mathrm{R}$ & & ha & 0 & 0 & 0 & 262 \\
\hline LVa/LK & & $\%$ & 0,00 & 0,00 & 0,00 & 6,64 \\
\hline
\end{tabular}


Nos valores da extensão total da abrangência de estados da erosão acelerada presente no solo (Tabela 2), observam-se diferenças que podem ser explicadas em razão da existência de condições distintas quanto ao solo, culturas estudadas, estágio de desenvolvimento das culturas, topografia e práticas de conservação do solo. As extensões totais da abrangência do estado 1 - erosão laminar ligeira/moderada em cada unidade de solo e comunidades de plantas novas e formadas, e as extensões totais representando a $\sum$ (estados 2 a 5) são representadas graficamente na Figura 1(a) e (b). O gráfico 1(a) refere-se à condição de melhor preservação do solo e o 1(b) à condição de maior degradação do solo, mostrando com maior evidência os contrastes entre comunidades novas e comunidades formadas e entre os Argissolos e Latossolos.

Estado de erosão 1

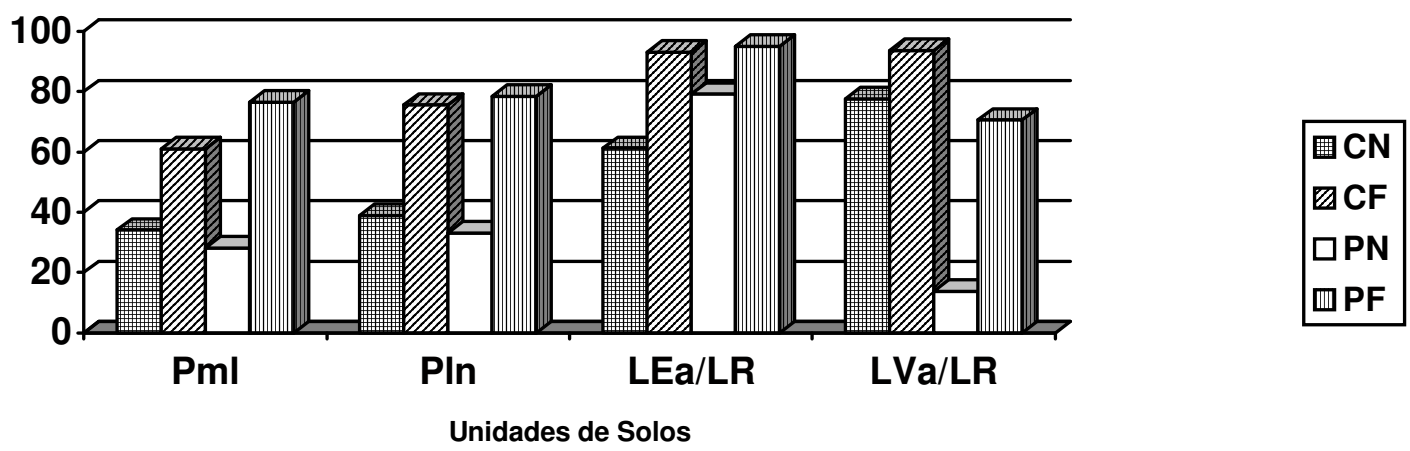

Estados de Erosão (2 a 5)

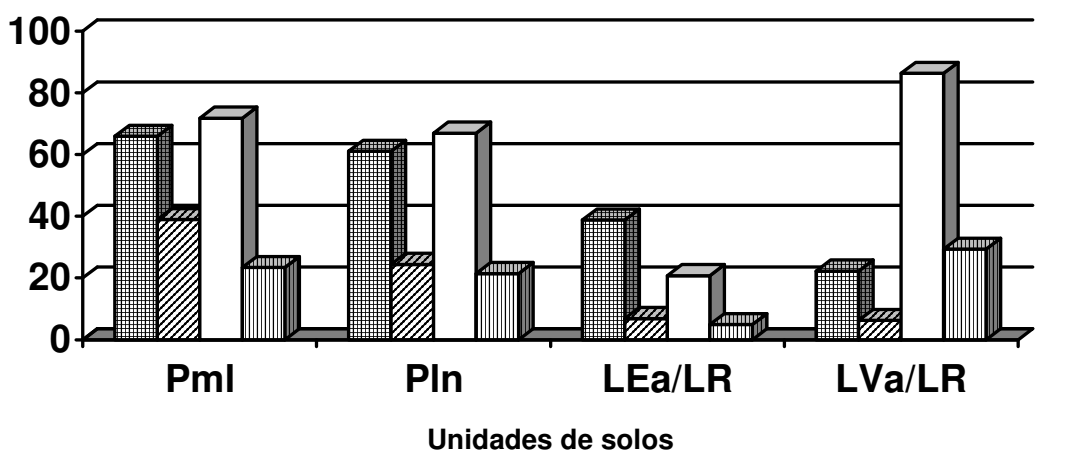

FIGURA 1. Extensões totais do estado 1 - erosão laminar/ligeira e $\sum$ (2 a 5) - erosão intensa a extremamente intensa ou severa.

As diferenças entre as áreas totais de abrangência dos canaviais e pomares de citros são, em geral, pouco evidentes, apesar da grande distinção dos aspectos fisionômicos duas culturas, principalmente quanto ao porte, silhueta, sistema radicular e densidade de cobertura do solo. Nesse aspecto, ressalta-se que a prática conservacionista (empregada comumente nos pomares de citros) de manutenção de vegetação herbácea nos espaços entre plantas deve ter contribuído para a melhoria da proteção do solo contra a erosão acelerada nos pomares formados, diminuindo, conseqüentemente, as diferenças entre canaviais e pomares de citros, confirmando-se afirmações de BAHIA (1992) e POLITANO et al. (1993) sobre a vantagem de manter o solo recoberto com vegetação herbácea possuindo alta densidade de cobertura do solo e sistema radicular fasciculado abundante.

Entre comunidades novas e formadas, constataram-se maiores abrangências dos estados de erosão 2 a 5 (condições severas a extremamente severas) nas comunidades novas, tanto nos canaviais 
como nos pomares de citros. Neles, principalmente na fase inicial, o solo permanece muito exposto, praticamente nu, oferecendo pequena resistência à ação erosiva do fluxo superficial da água.

Entre unidades de solos, as diferenças entre as áreas totais de abrangência foram muito mais evidentes entre os Argissolos e os Latossolos, confirmando-se de forma marcante as diferenças quanto ao risco de erosão acelerada avaliado por CHIARINI \& DONZELLI (1973) e BERTONI \& LOMBARDI NETO (1990). A maior extensão das áreas de abrangência das formas de erosão severa a extremamente severa nos Argissolos da região é plenamente justificada pela existência de topografia mais movimentada, dos horizontes superficiais arenosos, dos horizontes de subsuperfície de textura média a argiloso e das transições abruptas e claras entre horizontes superficiais e de subsuperfície.

Essas condições propiciam o aumento da intensidade da erosão e respectiva área de abrangência. Destaca-se que as condições mais graves foram observadas na unidade Argissolo PVA4, cuja topografia é mais movimentada e o perfil de solo é mais diferenciado que nas demais unidades, além de o mesmo ser geralmente menos espesso. Finalmente, registra-se que, na unidade LVa/LR, a erosão acelerada severa a extremamente severa nos pomares novos ocorria no final da década de 1980 com área total de abrangência destacadamente maior que o esperado para os Latossolos, sendo esse fato explicado pela pequena extensão dos pomares de citros nessa unidade de solos, cuja localização era também afetada pela entrada nas lavouras de enxurradas provenientes das estradas rurais, conforme pode ser constatado pela existência inclusive de voçorocas (estado 5).

\section{CONCLUSÕES}

Tanto os canaviais como os pomares de citros estão sujeitos à manifestação da erosão acelerada severa a extremamente severa, com grandes áreas de abrangência.

A influência dos estágios de desenvolvimento das culturas da cana-de-açúcar e dos citros foi mais marcante que a influência do tipo da cultura, sendo as comunidades novas mais sujeitas à erosão acelerada.

As diferenças entre classes Argissolos e Latossolos foram as mais evidentes, explicitando-se a grande necessidade de empregar, nessas condições, práticas conservacionistas eficazes no controle da erosão acelerada, principalmente as práticas que propiciam densidade alta de cobertura do solo com vegetação herbácea.

\section{REFERÊNCIAS}

AUDI, R. Estudo da cultura canavieira na região de Piracicaba. Bragantia, Campinas, v.24, n.18, p.203-18, 1965.

AYOADE, J.0. Introdução à climatologia para os trópicos. Rio de Janeiro: Bertrand Brasil, 1991. $332 \mathrm{p}$.

AZEVEDO, A. Brasil - a terra e o homem. São Paulo: Ed. Nacional, 1968. 607 p.

BAHIA, V.G. Fundamentos da erosão acelerada do solo (tipos, formas, mecanismos, fatores determinantes e controle. Informe Agropecuário, Belo Horizonte, v.16, n.176, p.25-31, 1992.

BARROS, W.D. Plantas na conservação dos solos brasileiros. Rio de Janeiro: Serviço Nacional de Informações Agrícolas do Ministério da Agricultura, 1961.53 p.

BELO, E. Modernização muda mapa agrícola de São Paulo. Folha de São Paulo, São Paulo, 12 fev. 1991. Agrofolha, p.1.

BERTONI, J.; LOMBARDI NETO, F. Conservação do solo. São Paulo: Ícone, 1990. 350 p. 
BRASIL. Ministério do Planejamento. Fundação Instituto Brasileiro de Geografia e Estatística. Departamento de Geografia. Folhas de Ribeirão Preto, Jaboticabal, Guariba, Pitangueiras, Taiúva, Pirangi, Taquaritinga, Roberto, Itápolis, Tabatinga e Matão, da Coleção Carta do Brasil. Rio de Janeiro: Instituto Brasileiro de Geografia, 1971. Esc. 1:50.000. Color.

CAMARGO, M.N.; KANT, E.; KAUFMANN, J.N. Sistema brasileiro de classificação de solos. Boletim Informativo da Sociedade Brasileira de Ciência do Solo, Campinas, v.12, n.1, p.11-13, 1987.

CASAGRANDE, A.A. Associação entre sistemas de preparo do solo e fosfatagem em cana-de-açúcar (Saccharum spp). Brasil Açucareiro, Rio de Janeiro, v.97, n.4, p.48-62, 1981.

CHIARINI, J.V.; DONZELI, P. L. Levantamento por fotointerpretração das classes de capacidade de uso das terras do Estado de São Paulo. Boletim Técnico do Instituto Agronômico, Campinas, p.1-20, 1973.

COMISSÃO DE SOLOS. Levantamento de reconhecimento dos solos do Estado de São Paulo. Boletim do Centro Nacional de Ensino e Pesquisas Agronômicas, Rio de Janeiro, n.12, p.1-639, 1960.

FORBES, R.D. Aerial photography (uses of aerial phographys in forestry). New York: Society American Foresters, 1961. 78 p.

FULLEN, M.A.; REED, A.H. Rainfall, run-off and erosion on bare arable soils in cost Shrosphire, England. Earth Surface Processes and Landforms, London, v.11, p.413-25, 1986.

JOLY, A.B. Conheça a vegetação brasileira. São Paulo: EDUSP/Polígono, 1970. 181 p.

KOFFLER, N.F. Inventário canavieiro com auxílio de fotografias aéreas - a grande região de Jaú, ano safra 1979-1980. Boletim Técnico Planalsucar, Piracicaba, v.2, n.4, p.1-22, 1980.

LOPES VERGARA, M.L. Manual de fotogeologia. Madrid: Servicio de Publicaciones de la Junta de Energia Nuclear, 1971. $286 \mathrm{p}$.

MODENESI, M.C.; JORDÃO, S. A erosão acelerada em Caçapava - SP. Boletim do Instituto Geológico, São Paulo, n.9, p.1-31, 1992.

OLIVEIRA, J.B. de; CAMARGO, M.N.; ROSSI, M.; CALDERANO FILHO, B. Mapa pedológico do Estado de São Paulo: legenda expandida. Campinas: Instituto Agronômico; Rio de Janeiro: Embrapa Solos, 1999. 64 p. mapa.

PENTEADO, M.M.; RANZANI, G. Aspectos geomorfológicos e os solos do município de Jaboticabal - SP. Geographica, Lisboa, n.25, p.41-61, 1971. (Separata)

POLITANO, W. Estudo da adequabilidade do emprego de bacias hidrográficas de $3^{a}, 2^{a}$ e $1^{a}$ ordens de magnitude na análise morfométrica aplicada a solos. 1992. 331 f. Tese (Livre-Docência em Topografia e Fotogrametria) - Faculdade de Ciências Agrárias e Veterinárias, Jaboticabal, 1992.

POLITANO, W. Manual do emprego de imagens aéreas na avaliação do terreno. Jaboticabal: FUNEP, 1994. 33 p.

POLITANO, W.; CORSINI, P.C.; DONZELLI, J.L. Caracterização e mapeamento da erosão antropogenética da superfície do Município de Monte Alto, SP. Científica, São Paulo, v.8, n.1 e 2, p.15-25, 1980.

POLITANO, W.; LOPES, L.R.; CORSINI, P.C.; AMARAL, C.; SAVASTANO, M. Erosão acelerada em solos podzólicos vermelho-amarelos sob ocupação com pomares de citros na região de Itápolis. In: CONGRESSO BRASILEIRO DE ENGENHARIA AGRÍCOLA, 22., 1993, Ilhéus. Anais ... Ilhéus: Sociedade Brasileira de Engenharia Agrícola, 1993. v.5, p.494-504. 
RANZANI, G. Subsídios à geografia da região de Piracicaba. Piracicaba: Instituto Histórico e Geográfico de Piracicaba, 1976. 79 p.

SÃO PAULO. Instituto Geográfico e Geológico. Mapa geológico do Estado de São Paulo. São Paulo: Instituto Geográfico e Geológico - IGG, 1974. Esc.1: 1.000.000. Color.

SÃO PAULO. Secretaria dos Negócios da Agricultura e Abastecimento. Levantamento pedológico semidetalhado dos solos do Estado de São Paulo - quadrícula de Ribeirão Preto. Rio de Janeiro: SUPREN/IBGE, 1981. Esc. 1: 100.000. Color.

SILVA, M.S.L.; RIBEIRO, M.B. Influência do cultivo contínuo da cana-de-açúcar em propriedades morfológicas e físicas de solos argilosos de tabuleiro do Estado de Alagoas. Revista Brasileira de Ciência do Solo, Campinas, v.16, n.3, p.397-402,1992.

TRICART, T. Les caracteristiques fondalmentales du système morphogenètique des pays tropicaux humedes. L'Information Geographic, Paris, v.4, p.155-69,1961. 